\title{
Carbon pricing revenues could close infrastructure access gaps
}

\author{
Michael Jakob ${ }^{\dagger, \varnothing, *},{\text { Claudine } \text { Chen }^{\dagger}, \text { Sabine Fuss }^{\dagger}, \text { Annika Marxen }}^{{ }^{\dagger}}{ }^{\dagger}$, Narasimha Rao $^{\ddagger}$, \\ Ottmar Edenhofer ${ }^{\dagger}, \varnothing, \S$ \\ ${ }^{+}$Mercator Research Institute on Global Commons and Climate Change, Torgauer Straße 12-15, 10829 \\ Berlin, Germany \\ ${ }^{\S}$ Technical University Berlin, Straße des 17. Juni 152, 10623 Berlin, Germany \\ ${ }^{\varnothing}$ Potsdam Institute for Climate Change Impact Research, Telegrafenberg 31, 14473 Potsdam, Germany \\ ${ }^{\ddagger}$ International Institute of Systems Analysis, Schlossplatz 1, A-2361 Laxenburg, Austria \\ *Corresponding author (jakob@mcc-berlin.net)
}

Abstract. Introducing a price on greenhouse gas emissions would not only contribute to reducing the risk of dangerous anthropogenic climate change, but would also generate substantial public revenues. Some of these revenues could be used to cover investment needs for infrastructure providing access to water, sanitation, electricity, telecommunications and transport. In this way, emission pricing could promote sustainable socio-economic development by safeguarding the stability of natural systems which constitute the material basis of economies, while at the same time providing public goods that are essential for human well-being. For a scenario that is consistent with limiting global warming to below $2^{\circ} \mathrm{C}$, we find that domestic carbon pricing (without redistribution of revenues across countries) has substantial potential to close existing access gaps for water, sanitation, electricity, and telecommunication. However, for the majority of countries carbon pricing revenues would not be sufficient to pave all unpaved roads, and for most countries in Sub-Saharan Africa they would be insufficient 
to provide universal access to all types of infrastructure except water. If some fraction of the global revenues of carbon pricing is redistributed, e.g. via the Green Climate Fund, more ambitious infrastructure access goals could be achieved in developing countries. Our paper also bears relevance for the design of climate finance mechanisms, as it suggests that supporting carbon pricing policies instead of project based finance might not only permit cost-efficient emission reductions, but also leverage public revenues to promote human development goals.

Keywords: Carbon pricing, infrastructure, economic development

\section{Introduction}

Recent research has furthered our understanding of the dangers of continued global warming (IPCC 2014a). A projected increase of the global mean temperature of $4^{\circ} \mathrm{C}$ or more in 2100 would entail potentially serious consequences for sea-level rise, water availability, agricultural productivity, and human health, in particular in developing countries (World Bank 2012). In order to prevent these impacts, considerable reductions of greenhouse gas (GHG) emission will be required, not only in industrialized, but also in developing economies (Jakob and Steckel 2014). The Kyoto Protocol included internationally binding commitments to reduce emissions for industrialized (Annex-I) countries, whereas developing and emerging (non-Annex-I) countries participated in a voluntary way under the principle of 'common but differentiated responsibilities'. With the Durban Agreement, states have agreed that a future climate treaty should entail efforts from all parties (UNFCCC 2011). All countries are requested to declare their 
intended efforts to reduce emissions (at least compared to projected future emissions) in the form of Intended Nationally Determined Contributions (INDCs). The most recent INDCs include targets by 187 countries, including all major emerging economies as well as numerous developing and least-developed countries. ${ }^{1}$

At the same time, poor countries face immediate challenges related to poverty reduction. For instance, globally many people lack access to basic infrastructure, including electricity, water, and sanitation. In view of these pressing issues, it is paramount to formulate climate policies in a larger sustainable development framework, which considers climate targets in combination with other development goals (Halsnæs and Garg 2011).

This paper examines the potential of carbon price revenues to finance infrastructure access. We argue that such an approach would constitute a promising option to advance sustainable development by mitigating greenhouse gas emissions and at the same time advancing socio-economic development. Hence, the results of this paper are closely linked to the discussion on Sustainable Development Goals (SDGs), and in particular the question of how to finance the post-2015 development agenda.

The rest of the paper is organized as follows: Section 2 reviews the literature, and Section 3 explains how we calculate revenues from carbon pricing and the costs to close infrastructure access gaps. Section 4 presents the results highlighting the implications of our proposal for different regions. Section 5 carries out a sensitivity analysis and Section

1 http://www4.unfccc.int/submissions/indc/Submission\%20Pages/submissions.aspx 
6 discusses caveats of our analysis as well as possible implementation issues. Section 7 concludes and presents policy implications.

\section{Literature Review}

In order to reduce greenhouse gas (GHG) emissions to a level that keeps the associated risks of climate change at a manageable level, a price on emissions is frequently emphasized as the most efficient policy (Edenhofer, Flachsland, et al. 2014). Popular approaches for carbon pricing include emission taxes and tradable permit schemes, as well as hybrid schemes (Goulder and Parry 2008). This paper argues that carbon pricing would not only contribute toward climate change mitigation, but could also advance human well-being by providing the financial means to promote access to basic types of infrastructure, including water, sanitation, electricity, telecommunication, and transport. This paper is related to several strands of literature. First, it follows previous studies estimating infrastructure investment needs. The dominant method in the literature to estimate investment requirements is to regress infrastructure investments on GDP (or vice versa), and then either project investment needs using growth forecasts, or estimate the level of investment that would maximize economic growth. Clearly, these estimates would not be suitable for our analysis, which focuses on universal access. In addition, the costs of reaching certain access goals, such as the Millennium Development Goals, are frequently provided on a regional instead of the country level. For these reason, we build our own cost estimates instead of relying on already existing ones. Earlier studies, on which our analysis builds, have examined the financial needs to 
provide universal electricity access (Pachauri et al. 2013) and the investments in water and sanitation required to achieve the Millennium Development Goals (Hutton et al. 2012), without focusing on the question of how these investments could be financed.

Second, our paper draws on the literature on carbon pricing. Most of this literature is concerned with the optimal choice of policy instrument, i.e. under which conditions it is more favourable to employ a price or a quantity instrument (Goulder and Parry 2008). Some recent studies have also highlighted the benefits of using revenues to either lower other (distortionary) taxes, e.g. on labour and capital (Goulder 2013), or for productive public investment (Edenhofer et al. 2015). Third, our paper is in line with contributions that emphasize the importance of combining natural boundaries with socio-economic limits into a broader notion of sustainable development (Griggs et al. 2013). For instance, taxing resource use and environmental externalities to finance infrastructure investments has been discussed as an approach to balance environmental and social objectives (Edenhofer, Kadner, et al. 2014; Jakob and Edenhofer 2014), and the potential of fossil fuel subsidy reform to finance infrastructure access is explored in Jakob et al. (2015). Fourth, our paper is related to literature on climate finance as well as development finance. Most analyses of climate finance (e.g. Haites 2011; Bowen 2011; Jakob et al. 2015) are primarily concerned with the question of how to raise revenues to finance mitigation and adaptation in developing countries. Our study relates to this literature by addressing the possibility of sizable financial transfers resulting from a global climate treaty that allocates the bulk of the costs of climate change mitigation to industrialized countries. However, we do not analyse the case in which carbon pricing 
revenues from industrialized countries are used to finance mitigation in developing countries, but focus on the case in which financial resources generated by means of carbon pricing within countries are employed to expand access to basic infrastructure. From this perspective, we follow the literature on innovative sources of development finance. For instance, Jha (2004) explicitly considers carbon taxes as a potential mechanism to raise resources. Likewise, a recent World Bank (2013) report on post-2015 development finance identifies carbon pricing as a promising mechanism to generate new funds.

Our paper is to our knowledge the first to empirically link the revenue raising aspect of carbon pricing with estimates of infrastructure investment needs. In particular, our calculations show what fraction of carbon pricing revenues would be required to achieve universal access to water, sanitation, electricity, telecommunication, and to pave all hitherto unpaved roads at the level of individual countries. Even though we present results for all countries for which data are available, the focus of our analysis is on developing countries, where infrastructure access gaps are most pronounced (industrialized countries in general display very high access rates for all types of infrastructure under consideration).

\section{Methodology and Data}


This section outlines the climate scenarios and their implied revenues from carbon pricing, as well as the data on infrastructure access and the associated costs to close access gaps across all world regions. ${ }^{2}$

\subsection{Scenarios of Climate Change Mitigation under Different Policies}

Estimating potential revenues from carbon pricing requires the use of scenarios of future emissions as well as carbon prices. Integrated Assessment Models (IAMs) constitute the most frequently employed tool to generate such scenarios (Luderer et al. 2011), which are inter alia used as a basis for the assessment of the Intergovernmental Panel on Climate Change target (IPCC 2014b). These models include a detailed description of the techno-economic characteristics of the energy system. Technological transformation pathways and mitigation costs are calculated by comparing business-as-usual projections (that assume no climate change mitigation will occur) with scenarios that impose a constraint on the atmospheric concentration of greenhouse gases (or the associated radiative forcing or temperature increase).

In order to identify differences as well as robust insights across a variety of IAMs, model comparisons are frequently carried out. The scenarios presented in this study are based on results from seven models used in the EMF-27 model comparison (Blanford, Kriegler, and Tavoni 2014; Krey et al. 2014; Kriegler et al. 2014) ${ }^{3}$. As the individual models use different regional aggregates, EMF-27 results are available for four macro-regions,

2 Access gaps and cost estimates are described in more detail in a companion paper (Fuss et al. 2015). Here, we only provide the most important insights.

3 Scenarios were obtained from IIASA's AR5 scenario database (https://secure.iiasa.ac.at/webapps/ene/AR5DB). The models included in EMF-27 are AIM-Enduse 12.1, GCAM 3.1, IMAGE 2.4, MESSAGE V.4, POLES EMF27, REMIND 1.5, and WITCH EMF27. 
namely Asia, Latin America and the Caribbean (LAM), Middle East and Africa (MAF) as well as the members of the OECD in the year 1990 (OECD90).

Figure 1 provides an overview of carbon prices and emissions in the year 2020 for the $450 \mathrm{ppm}-\mathrm{CO}_{2}$-eq. ${ }^{4}$ (ppm denote parts-per-million, i.e. the ratio of molecules of $\mathrm{CO}_{2}$ relative to other gases in the atmosphere) stabilization scenario, which has an even chance of achieving the $2^{\circ} \mathrm{C}$ target. The scenarios assume a globally harmonized carbon price and full availability of low-carbon energy technologies (such as renewables, nuclear, and carbon capture and storage (CCS)). The models project roughly similar emissions ${ }^{5}$ in 2020 (x-axis) for a given region (with the exception of negative emissions in two regions for the GCAM model $\left.{ }^{6}\right)$, but a large variation in carbon prices (y-axis), which range from less than US\$ 20 to more than US\$ 120 per ton of $\mathrm{CO}_{2}$ (throughout the analysis, we use constant year 2005 US\$). This broad span is mostly explained by differences in technological assumptions (e.g. on technology costs or the speed of deployment of certain low-carbon energy sources) and economic mechanisms across models.

[Figure 1: Emissions and carbon prices in the year 2020 for the 450ppm scenarios]

$4 \mathrm{CO}_{2}$-eq. denotes $\mathrm{CO}_{2}$-equivalents, a composite of $\mathrm{CO}_{2}$ as well as other $\mathrm{GHGs}$, such as methane or nitrous oxide, which establish a common metric to assess the effect of these gases on the global mean temperature.

5 All emissions referred to in this study are total $\mathrm{CO}_{2}$ emissions, i.e. including $\mathrm{CO}_{2}$ emissions from land use change and industrial processes, but excluding non- $\mathrm{CO}_{2} \mathrm{GHGs}$, such as methane.

6 Negative emissions occur if more emissions are taken out of the atmosphere by e.g. afforestation or use of biomass in combination with CCS than are released by e.g. the combustion of fossil fuels. 
Besides differences between models, the ambition of the stabilization target as well as restrictions on availability of certain technologies influence the carbon price. For this reason, we also briefly analyze 550ppm stabilization scenarios, which have an even chance of limiting global warming to below $3^{\circ} \mathrm{C}$, and scenarios in which CCS is assumed to be unavailable as well as scenarios with restricted availability of biomass. A less ambitious mitigation target will thus result in a lower carbon price, whereas foregoing the use of CCS, or restricting biomass use, will raise it.

In order to get a better understanding of the determinants of carbon prices, we perform a simple regression analysis, in which the year 2020 carbon price in a stabilization scenario (for $450 \mathrm{ppm}$ and 550ppm, and with full technological availability, limited biomass, as well as without CCS, respectively) is the dependent variable. We regress carbon prices in each scenario on dummy variables for the stabilization target (with $550 \mathrm{ppm}$ as the lower-bound benchmark and PPM450 taking on the value of 1 for scenarios aiming at atmospheric GHG stabilization at $450 \mathrm{ppm}$ ), technological availability (with FullTech as the benchmark, and NoCCS and LimBio denoting scenarios without CCS or limited availability of biomass) and a model-specific dummy variable (which gives the ceteris paribus difference to the average) using ordinary least squares (OLS). As technological options can be expected to be of higher relevance for more ambitious stabilization targets, we further include interaction terms for the dummy variables on the stabilization target and technological availability (PPM450_NoCCS and PPM450_LimBio). The results reported in Table 1 should not be regarded as a draw from 
a random sample but rather be interpreted as conditional means. Hence, standard errors and significance levels are uninformative.

[Table 1: Results of regression analysis]

Our preferred specification includes model-specific dummies as well as interaction terms for stabilization target and technology availability (first column), as this specification contains the highest number of explanatory variables and hence permits the most detailed explanation of differences in carbon prices across scenarios. The results indicate the following: first, for the case of full availability of technologies, mitigation costs in the 450ppm scenario are on average about US\$ 28 higher than for the 550ppm scenario. Second, for the 550ppm scenario, excluding CCS and limiting biomass use raises the carbon price moderately, by roughly US\$ 8 and US\$ 3 , respectively. Third, these technologies are significantly more important for the more ambitious $450 \mathrm{ppm}$ scenario. That is, not having CCS available would then raise carbon prices by more than US\$108, and limiting biomass use would raise carbon prices by almost US\$20. Finally, as already highlighted in Figure 1, there is a pronounced difference in carbon prices between models, with the lowest values for GCAM, and the highest for REMIND.

\subsection{Carbon Pricing Revenues and International Transfers}

For our revenue projections, we take the $450 \mathrm{ppm}$ scenario with full technological availability as a benchmark scenario (alternative scenarios are explored in the sensitivity analysis). We take emissions and carbon prices from the POLES model, as this model 
yields the median revenues of the seven EMF-27 models. Under this scenario, global energy-related $\mathrm{CO}_{2}$ emissions keep rising (albeit slowly) from $30.6 \mathrm{GtCO}_{2}$ in 2010 to 31.7 $\mathrm{GtCO}_{2}$ in 2020 , before starting to decline. In 2030 , they amount to $23 \mathrm{GtCO}_{2}$. The implied carbon price is US\$ 5 per ton of $\mathrm{CO}_{2}$ in 2010 , rising by nearly $20 \%$ per year. In the year 2020 , it amounts to US\$ 40 per ton of $\mathrm{CO}_{2}$, and in 2030 to US\$ 175 per ton of $\mathrm{CO}_{2}$. As we require revenues on the country level for our analysis, we apply annual regional emission growth rates in the period 2010-2030 from POLES to extrapolate from emissions in the year 2010. Further, as the model scenarios provide emission prices in 10-year intervals only, we estimate annual prices by assuming a constant rate of increase from 2010 to 2030 .

With these assumptions, we arrive at global revenues of US\$ 23.8 trn over the period 2015-2030, or on average US\$ 1.6 trn per year. In Section 4, which presents the main results of our analysis, we focus on revenues that would occur if a globally uniform carbon price would be implemented in each country, without transfer of financial resources across countries. For instance, India would then on average raise US\$ 115 bn per year, and China more than US\$ $480 \mathrm{bn}$. For countries that are low emitters and for which rather low emission growth is expected, however, carbon pricing would constitute a limited source of public revenue. This is particularly true for numerous countries in Sub-Saharan Africa and Central Asia, for which annual revenues would lie below US\$ 1 bn per year. Figure 2 provides an overview of average annual revenues on a regionally aggregated basis for the benchmark scenario and compares these with revenues under different assumptions on the stabilization target and technological availability. 
Interestingly, revenues are quite similar across scenarios, which is explained by the fact that higher emissions (e.g. under a laxer reduction target) are compensated by lower carbon prices, and vice versa. ${ }^{7}$ The main exception is the $450 \mathrm{ppm}$ NoCCS scenario. If the option to sequester emissions is not available in the second half of the $21^{\text {st }}$ century, more rapid reductions are required earlier (i.e. before 2030) that are not fully compensated by a higher emission price.

[Figure 2: Average annual revenues from carbon pricing under different stabilization scenarios and technology assumptions]

This pattern of how revenues accrue to individual world regions could change dramatically if some of the revenues from carbon pricing were redistributed across countries. A central aspect of the discussion of equitable climate policy considers the burden sharing scheme, i.e. how the global costs of emission reductions are to be divided (Mattoo and Subramanian 2012). For this reason, we discuss three alternative mechanisms of dividing the revenues from carbon pricing. Following Raupach et al. (2014), we look at scenarios in which the share of revenues is determined (i) in proportion to actual emissions ( $\mathrm{X}=0$, no redistribution), (ii) in proportion to population ( $X=1$, equal per-capita), and (iii) the average $(X=0.5)$ of the former two schemes, reflecting different notions of justice and political feasibility incorporated in the scheme for revenue sharing (or burden sharing, respectively).

7 Likewise, one should expect delayed climate action to result in comparable revenues, as (i) a higher carbon price would be necessary in later years to bend the emission trajectory downward, and (ii) emissions would have increased by then, such that there would be a larger tax base. 
[Figure 3: Average annual revenues from carbon pricing under different allocation schemes]

Figure 3 shows the average annual revenues under these revenue-sharing schemes. East Asia \& Pacific, Europe \& Central Asia and North America would be large net payers. Under the scheme $X=0.5$ (i.e. scheme iii), these regions would provide annual financial transfers of about US\$ $90 \mathrm{bn}$, US\$ $50 \mathrm{bn}$, and US\$ $80 \mathrm{bn}$, respectively (and twice that amount under $X=1$, i.e. scheme ii). The aggregate transfers would hence significantly exceed current levels of official development assistance (ODA), which amounted to about US\$ 135 bn in 2013 (OECD 2014). By contrast, Sub-Saharan Africa would receive more than US\$ $100 \mathrm{bn}$, and South Asia more than US\$ 120 bn per year (and twice that amount under scheme ii).

The extent to which carbon pricing revenues could contribute towards existing infrastructure access gaps will be the subject of the following section. For the analysis, we will focus on the 450ppm scenario with full technological availability, and the scheme in which revenues are derived exclusively by means of domestic carbon pricing (i.e. $X=0$ ). The effect of alternative revenue sharing schemes can then be inferred from calculating its ratio relative to the case of $X=0$ (i.e. if revenues under a given scheme are, say, twice as high as under domestic carbon pricing, only half of the fraction indicated in our analysis below will be required to achieve universal access to a given infrastructure). 


\subsection{Access to Infrastructure}

For the purpose of this paper, we regard infrastructure as the basic physical structures needed for the operation of a society. As highlighted by a recent United Nations report, infrastructure constitutes the largest share of SDG investment needs (UNTT Working Group on Sustainable Development Financing 2013). Achieving universal access to key types of infrastructures is a necessary, albeit not a sufficient, condition for reaching the SDGs. The goal of this study is to determine whether revenues from emission pricing would be sufficient to ensure that this necessary condition is met by enabling universal (i.e. $100 \%$ ) access to water, sanitation, electricity and telecommunication, and allow paving of all unpaved roads ${ }^{8}$.

Access to water refers to the share of the population using an improved drinking water source, such as piped water, public taps or standpipes, tube wells or boreholes (World Bank 2014). Improved sanitation facilities include piped sewer systems, septic tanks, pit latrines, and composting toilets (World Bank 2014). Electricity access measures the percent of households with an electricity connection (Pachauri et al. 2013). Note that providing universal electricity access would, even if conventional energy sources are used, only have a small impact on global emissions and hence not contradict the goal of safeguarding environmental quality (Pachauri 2014; Rao, Riahi, and Grubler 2014).

\footnotetext{
8 Access to roads is essential for e.g. access to markets (Jacoby 2000).We suppose that all unpaved roads are in place because there is an actual need for them. Even though these roads do not necessarily need to be paved to ensure access, paving would substantially ease transportation. Hence, the requirement of paving all unpaved roads considered in this paper can be regarded as an upper limit for the investment needs required to ensure access to transportation services. Quantification of investment needs for public transportation is, due to data limitations, beyond the scope of this paper.
} 
For telecommunication, having a mobile phone plus 10 minutes of airtime per day were taken as a target (ITU 2014). We do not consider the construction of landlines, as it can be expected that the largest part of new telecommunication infrastructure will be mobile. In addition, costs for landlines are not straightforward to estimate, as they likely depend on population density and geographical factors.

Finally, for transportation, we assume paving all currently unpaved roads as the target to be achieved (World Bank 2014).

These types of infrastructure are essential for human development in the sense of creating the capabilities to allow people to pursue their individual aims (Drèze and Sen 2013) and are also crucial determinants of multi-dimensional deprivation (Alkire 2002) and social inequality (Binelli, Loveless, and Whitefield 2015). Undoubtedly, other types of infrastructure such as education and healthcare are also crucial for development. However, we limit our analysis to the above types of infrastructure, as a definition of universal access is more straightforward than for health or education, reliable cost estimates for the latter areas are not readily available on a global basis and we perceive them to more basic and conditioning some of the softer types of infrastructure.

[Table 2: Share of population lacking access to electricity, water, sanitation, telecommunication and share of unpaved roads]

Table 2 provides an overview of access gaps aggregated at the regional level. These gaps are in general most pronounced for Sub-Saharan Africa, where more than one third of 
the population does not have access to water, and more than two thirds lack access to sanitation and electricity. Likewise, in South Asia, more than $60 \%$ lack access to sanitation, and more than two thirds do not have access to telecommunication.

For our analysis, we examine a scenario in which infrastructure investments are undertaken over a horizon of 15 years, corresponding to the 2015-2030 timeframe of the Sustainable Development Goals (Griggs et al. 2013). We assume that without intervention, the share of the population lacking access to a certain infrastructure in the year 2030 would be the same as in the year 2010 (hence our estimates can be considered conservative, as with economic growth it can be expected that access gaps start to shrink as part of the economy's development process; see also Section 6). The access gap for each country is then calculated by multiplying this share with the medium scenario of the population forecast for 2030 from the United Nations World Population Prospects (UN 2013).

\subsection{Costs of Providing Infrastructure}

The costs for infrastructure access and paving roads were collected from the literature. Where data for individual countries was not available, we used regional averages. For recurrent costs (i.e. costs that occur on a regular basis, such as maintenance and depreciation), we assumed that infrastructure build-up is distributed equally over the considered 15-year horizon. This yields an average time of 7.5 years for which these expenses need to be met. 
For the cost estimate of enabling universal access to clean water and sanitation, we rely on the World Health Organization (WHO) study by Hutton et al. (2012). This study estimates the incremental costs of extending access to water supply and sanitation, taking into account investments costs (including planning, construction, protection of water sources, training etc.) as well as recurrent costs.

For costs of electricity access, which can be achieved by means of grid expansion or decentralized sources, we employ cost projections from the energy system model MESSAGE-Access (Pachauri et al. 2013) as the basis for our calculation. MESSAGE-Access is a household fuel choice model that explicitly accounts for heterogeneous economic conditions and the preferred energy choices of poor populations living in rural and urban settings, based on data from nationally representative consumer surveys.

Concerning the costs of paving unpaved roads, we use data from the International Energy Agency (2013). This study collects aggregate costs of construction and maintenance for different types of roads (e.g. expressways, motorways, and access roads) in different locations (e.g. urban, interurban, and rural) on a regional basis.

Finally, costs for providing access to mobile connections is assumed to be 150 US\$ fixed costs per connection, which is in line with the range of different studies reported in Rothman et al. (2014). For the cost of usage, we assume a price of 2 cents per minute of air time.

At global scale, our cost calculations indicate that universal access to water could be achieved by investing US\$ 190 bn per year, US\$ 370 bn could cover universal access to sanitation, and US\$ 430 bn could finance universal access to electricity. Providing 
universal access to telecommunication would amount to US\$ $2.6 \operatorname{trn}$ annually, and paving all unpaved roads to US\$ $8.7 \mathrm{trn}$.

The next section examines to which extent these infrastructure investment needs could be covered by revenues from carbon pricing.

\section{Results}

Our key results are shown in Figure 4, which displays the share of carbon pricing revenues that would need to be invested in a particular type of infrastructure over a period of 15 years to achieve universal access. Even though we conduct our analysis for all countries for which data are available, the results are most relevant for developing countries, for which lack of access plays a crucial role for socio-economic development.

A darker color denotes that a larger share of the revenues would be required, i.e. a lower potential of carbon pricing to close access gaps. Dark purple indicates shares greater than one, which means that revenues would be insufficient to fully close existing access gaps. White denotes countries that already display universal access, such that a zero share of carbon pricing revenues would be required. Countries for which no data are available are shaded in grey.

For water (panel a), the results indicate that carbon pricing revenues would be sufficient to cover the costs of universal access for all countries except for Chad, the Democratic Republic of Congo, Lesotho, Mali, and Somalia. Whereas the required share is rather low $(<10 \%)$ for most countries, some countries in Sub-Saharan Africa and South-East Asia would require $20 \%$ or more of their carbon pricing revenues to achieve universal access. 
A notable exception in Latin America is Ecuador, where the required share is more that $30 \%$, which is due to the rather large access gap as well as still low emissions, which result in low carbon pricing revenues.

For sanitation (panel b), carbon pricing revenues would be more than sufficient to cover investment needs in all of South Asia and Latin America. Notably, India would require only about $4 \%$, Sri Lanka $2 \%$, and Bangladesh as well as Pakistan each about $11 \%$ of their revenues to close the access gaps. Given that more than $60 \%$ of South Asia's population lacks access to sanitation, this potential is quite remarkable. For Sub-Saharan Africa, there is less potential, as carbon pricing revenues would exceed the infrastructure investment needs for sanitation for about half of the countries in the region. However, Senegal, Cabo Verde, Swaziland, Zimbabwe, Gabon, and Angola could all achieve universal access to sanitation for $10 \%$ or less of their carbon pricing revenues.

For electricity infrastructure (panel c), more than half of the countries in Sub-Saharan Africa could not meet their entire investment needs by means of carbon pricing, and the majority of the remainder would require $50 \%$ or more. On the other hand, practically all countries in Latin America (except Haiti, Guatemala and Nicaragua) could achieve universal access at $10 \%$ or less of their carbon pricing revenues, owing to the lower access gaps as well as lower costs per connection (which are due to higher population densities in these areas compared to Africa) $)^{9}$. For Asia, there is a wide range of required investments in electric infrastructure, ranging from less than $1 \%$ in Indonesia and Mongolia to almost 99\% in Timor-Leste.

9 Note that providing universal electricity access would only have a small impact on emissions and hence not contradict the goal of safeguarding environmental quality (Pachauri 2014; Rao, Riahi, and Grubler 2014). 
For telecommunication (panel d), most Sub-Saharan African countries would require investments far beyond the revenues that could be obtained by carbon pricing (for many countries in this regions, investment needs for information and communication technology (ICT) exceed carbon pricing revenues by a factor of ten or more). Despite that finding, carbon pricing could still be an important ingredient of policies to expand access to telecommunication, especially when one takes into account that only a certain fraction of ICT infrastructure will need to be financed by public budgets. In addition, technological progress is likely to result in lower costs in the future, and economic growth can be expected to contribute to increased access (the implications of these aspects for our results are discussed in more detail in Section 6). For most of South Asia, carbon pricing revenues would be sufficient to achieve universal access to telecommunication, but a rather high share of about $50 \%$ or more would be needed. Given that some part of revenues may be dedicated to other purposes, the full amount of investment required for ICT infrastructure might then not be available. By contrast, most countries in Latin America could provide universal access to telecommunication for about $10-20 \%$ of their carbon pricing revenues.

Finally, the investment needed to pave all unpaved roads (panel e) would exceed carbon pricing revenues several-fold for more than 30 countries. This concerns not only countries in Sub-Saharan Africa, which display low carbon pricing revenues, but also several countries with higher revenues in Latin America, South and South-East Asia as well as Eastern and Central Europe and New Zealand. For the latter countries, this result is due to the relatively high absolute amount of unpaved roads. In any case, it should be 
emphasized that paving all unpaved roads is a rather stringent requirement that likely goes beyond what can be deemed necessary to provide basic access to transport services.

In summary, our results indicate that carbon pricing could provide revenues to achieve universal access to water, sanitation, and electricity during the period 2015-2030 in most parts of the world. Yet, our analysis also highlights that carbon pricing only has limited potential to close access gaps in Sub-Saharan Africa, which is mostly explained by the low emissions and hence low revenues in this region. Different schemes of how revenues are shared could, however, drastically change this result. For instance, if the above calculations are carried out under the assumption that global carbon pricing revenues are distributed by the average between 'no redistribution' and 'equal percapita' (i.e. the $X=0.5$ scheme), revenues are sufficient to finance universal access to any single type of infrastructure except roads in all parts of the world, or access to water, sanitation, and electricity combined. The results of this analysis are shown Figure A1 of the Appendix.

[Figure 4: Share of carbon pricing revenues required to finance universal access to infrastructure]

In the next section, we assess the robustness of our results by testing for the impact of different assumptions regarding the stabilization target and availability of low-carbon technologies, both of which have important consequences for the carbon price. 


\section{Sensitivity Analysis}

The results presented above were derived for a scenario that assumes stabilization of the atmospheric GHG concentration at 450ppm (i.e. an even chance of staying below $2^{\circ} \mathrm{C}$ ) with a full portfolio of technology options. As the use of some technologies might be restricted either because they might not be socially acceptable, more costly than expected, technologically infeasible, or associated with unforeseen risks or unacceptable trade-offs, we also examine two alternative settings, in which the use of biomass is limited (LimBio), and in which CCS is assumed to be unavailable (NoCCS). Furthermore, we also examine scenarios aiming at less ambitious climate targets, namely 550ppm (i.e. an even chance of not exceeding $3^{\circ} \mathrm{C}$ ), and vary the costs of infrastructure investment by $+/-50 \%$. This leaves us with a total of 18 scenarios $(3 \times 3 \times 2$ for technology assumptions, assumed investment costs, and the stabilization target). The required shares of carbon pricing revenues for each infrastructure are shown on a regional level in Figure 5 (a value of, say, 0.1 states that $10 \%$ of carbon pricing revenues would be required to achieve universal access, and values larger than one indicate that revenues would be insufficient to fully cover investment needs).

[Figure 5: Results of sensitivity analysis]

This analysis shows that for water and sanitation investment needs could - on aggregate - be fully met by carbon pricing revenues for all regions, even under scenarios in which 
relatively low revenues are generated for regions with large access gaps. For electricity, this is true for all regions except Sub-Saharan Africa (where revenues would be insufficient for scenarios with low revenues and high investment costs). This regionally aggregated perspective does not take into account the underlying differences between individual countries. For instance, even under the most optimistic assumptions on revenues as well as costs, a large number of countries in Sub-Saharan Africa would not be able to fully meet their investment needs for sanitation or electricity.

This sensitivity analysis also highlights that only under the most optimistic of assumptions (i.e. high revenues and low investment costs) carbon pricing revenues would be sufficient to finance universal access to telecommunication in Sub-Saharan Africa. The same is true for paving all unpaved roads in Latin America and South Asia. This optimistic scenario seems especially unlikely, as (perhaps in contrast to ICT equipment) significant cost reductions in road construction do not seem plausible. For Sub-Saharan Africa, by contrast, carbon pricing revenues would be insufficient to pave all roads even under the most favourable assumption, where total costs exceed revenues more than two-fold (and more than twelve-fold under the most pessimistic set of assumption).

\section{Discussion}

One important qualification to our analysis is that it does not take into account the intrinsic link between infrastructure and economic growth. On the one hand, continued economic growth can be expected to help closing existing access gaps, even without 
new finance from innovative sources, such as carbon pricing. Including this aspect into our analysis would not only require plausible assumptions on future economic growth a major challenge in its own right - but also a clear understanding of the determinants of infrastructure access. The related literature suggests considerable heterogeneity across countries far beyond what is explained by differences in income levels (Onyeji, Bazilian, and Nussbaumer 2012; Winkler et al. 2011). For this reason, projecting future access gaps as a function of assumed growth rates would probably do more to confound than to clarify our analysis. At the same time, it is plausible that infrastructure investments spur economic growth. Previous literature has highlighted the economic benefits of e.g. electrification (Grogan and Sadanand 2013) and roads (Shami 2012) for select countries. On the cross-country level, several authors have found large returns to infrastructure investments (Calderon and Serven 2014; Gupta et al. 2014). Yet, the coefficients estimated in these studies present an average over the sample and may hide a large degree of underlying heterogeneity. For this reason, it seems premature to simply apply these coefficients to assess how economic growth responds to infrastructure investment, as such an approach would need to assume that all countries respond in an identical way.

A further caveat is that not all infrastructure investments necessarily need to be financed by the government, but could see involvement by the private sector. The optimal composition of private and public provision of infrastructure services depends on the assessment of potential trade-offs between equity and efficiency considerations (Birdsall and Nellis 2003). In any case, with participation of the private sector, a lower 
share of carbon pricing revenues than the one indicated in our analysis would be required to achieve universal access. This point might be particularly relevant for ICT infrastructure, where substantial involvement of the public sector is common.

Due to both reasons stated above (i.e. economic growth and involvement of the private sector), our results should be regarded as conservative, as they indicate the share of carbon pricing revenues that would be sufficient to achieve universal access even if no improvements due to economic growth would occur, and even if the infrastructure investments were fully funded by the public sector.

Obviously, alternative uses of the proceeds from carbon pricing are conceivable. For instance, a certain fraction could be used for dedicated green technology policies, such as R\&D subsidies or feed-in-tariffs (Dresner et al. 2006). Investing revenues from carbon pricing in infrastructure could also create synergies between climate change mitigation and adaptation, as areas lacking access to infrastructure services are particularly vulnerable to climate impacts (Malik and Smith 2012). Our analysis does not make explicit assumptions on what fraction of carbon pricing revenues will be directed toward these purposes. By calculating the share of revenues that would be required to achieve universal access to a particular type of infrastructure, it is left for the readers' judgement whether such revenue recycling is deemed to be realistic. In any case, it seems likely that investments that yield large development benefits while only requiring a few percent of carbon pricing revenues would stand a good chance of becoming actually implemented. Another aspect that needs to be considered is the practical implementation of a scheme that uses carbon pricing revenues for infrastructure investment. Clearly, carbon pricing 
imposes additional costs on consumers of energy services and are thus frequently opposed, at least in countries without either strong civil society or a well-established green industry (Never and Betz 2014). However, if combined with appropriate spending policies, these additional costs can easily be more than compensated by the benefits of infrastructure access, provided that high quality service delivery can be ensured by holding governments accountable for public sector performance (Fox 2015). Under such circumstances, recent research suggests that by earmarking revenues for uses that are regarded as worthwhile by the population, political feasibility of market-based environmental policies can be increased (Kallbekken, Kroll, and Cherry 2011). Hence, redirecting carbon pricing revenues to infrastructure investments could provide a mechanism that commits policy-makers to use these revenues in a pre-determined way and thus reduce opportunities for embezzlement. In addition, some fraction of the revenues from carbon pricing may be employed to compensate political losers, e.g. by lowering other taxes.

Finally, one could question the assumption of carbon pricing in developing countries in the near future. Without carbon prices, there would (at least in the absence of transfers from industrialized countries) of course be no revenues that could be invested in infrastructure. However, it seems highly unlikely that the $2^{\circ} \mathrm{C}$ target can be reached without carbon pricing in developing countries, and we point out that the potential to promote human development by investing the associated revenues could yield an incentive to implement carbon prices. We are rather optimistic that at least some carbon pricing in developing countries will prevail in the near future, as China, Korea, 
Mexico, Chile and South Africa have either announced or already implemented policies that put a price on carbon (World Bank and Ecofys 2015), and REDD+ will likely generate additional for developing countries' government budgets (Koch et al. 2015). Furthermore, developing countries would receive funds to meet infrastructure investment needs if some part of carbon pricing revenues was transferred across countries, in line with the principle that the full incremental costs of climate change mitigation are to be covered by industrialized countries (UNFCCC 1992). Arguably, large financial transfers might be a politically contentious issue. Yet, it seems unlikely that developing countries will cover the full costs of emission reductions without any financial assistance, such that at least some support from industrialized countries, e.g. via the Green Climate Fund (GCF) (UNFCCC 2010), should be expected if ambitious climate change mitigation is realized. Even though to date it is unclear in how far the envisaged climate finance of US\$ 100 bn per year that shall be mobilized (by the year 2020) will indeed materialize, the GCF currently has US\$ 10.2 bn at its disposal to support mitigation and adaptation in developing countries. ${ }^{10}$ For this reason, at least some transfers are almost certain to occur. As a consequence, our benchmark scenario, which assumes no redistribution, should be regarded as a conservative estimate of the potential of carbon pricing revenues to finance infrastructure access.

\section{Conclusions}

\section{0}

http://unfccc.int/cooperation_and_support/financial_mechanism/green_climate_fund/items/5869.php 
In this paper we have examined how climate change mitigation and infrastructure access policies can be combined into a broader perspective of sustainable development. The results have highlighted the considerable potential of carbon pricing to generate revenues to close access gaps for water, sanitation, electricity, and telecommunications and to improve existing transport infrastructure.

The respective potentials show substantial variation across types of infrastructures and world regions. For the majority of countries, carbon pricing revenues would likely be sufficient to provide universal access to water, sanitation, electricity, and telecommunications, whereas investment needs for paving all unpaved roads would exceed carbon pricing revenues in most cases. Our results also highlight that for the majority of countries in Sub-Saharan Africa carbon pricing revenues would be insufficient to achieve universal access to all types of infrastructure other than water. This observation is due to the high access gaps as well as low carbon pricing revenues (resulting from low emissions) in this region.

In any case, it can be expected that the extent to which human development issues are taken into account in the emerging global climate regime will be crucial for its success or its failure. The results presented in this paper allow for a deeper understanding of the role of carbon pricing for human development. They might also help to guide the design of climate finance mechanisms. Currently, the discussion around climate finance mainly revolves around the envisaged level of funding, with little attention being paid to the question of how to ensure that the funds are spent effectively. For instance, experience with the Clean Development Mechanism (CDM), which was used to incentivize emission 
reductions in developing countries under the Kyoto framework, suggests that this approach has not resulted in serious emission reductions (Schneider 2009). Hence, using available funds to support carbon pricing instead of project-based finance might not only permit cost-efficient emission reductions, but also leverage public revenues to promote human development goals.

\section{References}

Alkire, Sabina. 2002. "Dimensions of Human Development." World Development 30 (2): $181-205$.

Binelli, Chiara, Matthew Loveless, and Stephen Whitefield. 2015. “What Is Social Inequality and Why Does It Matter? Evidence from Central and Eastern Europe." World Development 70 (June): 239-48. doi:10.1016/j.worlddev.2015.02.007.

Birdsall, Nancy, and John Nellis. 2003. "Winners and Losers: Assessing the Distributional Impact of Privatization." World Development 31 (10): 1617-33.

Blanford, Geoffrey J., Elmar Kriegler, and Massimo Tavoni. 2014. "Harmonization vs. Fragmentation: Overview of Climate Policy Scenarios in EMF27." Climatic Change 123 (3-4): 383-96. doi:10.1007/s10584-013-0951-9.

Bowen, Alex. 2011. “Raising Climate Finance to Support Developing Country Action: Some Economic Considerations." Climate Policy 11 (3): 1020-36. doi:10.1080/14693062.2011.582388. 
Calderon, Cesar A., and Luis Serven. 2014. "The Effects of Infrastructure Development on Growth and Income Distribution." Annals of Economics and Finance 15 (2): 52134.

Dresner, Simon, Louise Dunne, Peter Clinch, and Christiane Beuermann. 2006. "Social and Political Responses to Ecological Tax Reform in Europe: An Introduction to the Special Issue." Energy Policy 34 (8): 895 - 904. doi:http://dx.doi.org/10.1016/j.enpol.2004.08.043.

Drèze, Jean, and Amartya Sen. 2013. An Uncertain Glory: India and Its Contradictions. Princeton University Press.

Edenhofer, Ottmar, Christian Flachsland, Michael Jakob, and Kai Lessmann. 2014. "The Atmosphere as a Global Commons - Challenges for International Cooperation and Governance." In Semmler, W., L. Bernard (ed.): The Handbook on the Macroeconomics of Climate Change. Oxford University Press.

Edenhofer, Ottmar, Michael Jakob, Felix Creutzig, Christian Flachsland, Sabine Fuss, Martin Kowarsch, Kai Lessmann, Linus Mattauch, Jan Siegmeier, and Jan Christoph Steckel. 2015. "Closing the Emission Price Gap." Global Environmental Change.

Edenhofer, Ottmar, Susanne Kadner, Christoph von Stechow, Gregor Schwerhoff, and Gunnar Luderer. 2014. “Linking Climate Change Mitigation Research to Sustainable Development." In Handbook of Sustainable Development. Second Edition. Edited by Giles Atkinson, Simon Dietz, Eric Neumayer and Matthew Agarwala. DOI $\quad 10.4337 / 9781782544708.00044$. 
Fox, Jonathan A. 2015. "Social Accountability: What Does the Evidence Really Say?" World Development 72 (August): 346-61. doi:10.1016/j.worlddev.2015.03.011. Goulder, L. H., and I. W. H. Parry. 2008. "Instrument Choice in Environmental Policy." Review of Environmental Economics and Policy 2 (2): 152-74. doi:10.1093/reep/ren005.

Goulder, Lawrence H. 2013. "Climate Change Policy's Interactions with the Tax System." Energy Economics 40 (December): S3-S11. doi:10.1016/j.eneco.2013.09.017. Griggs, David, Mark Stafford-Smith, Owen Gaffney, Johan Rockström, Marcus C. Öhman, Priya Shyamsundar, Will Steffen, Gisbert Glaser, Norichika Kanie, and lan Noble. 2013. “Policy: Sustainable Development Goals for People and Planet." Nature 495 (7441): 305-7.

Grogan, Louise, and Asha Sadanand. 2013. "Rural Electrification and Employment in Poor Countries: Evidence from Nicaragua." World Development 43 (March): 25265. doi:10.1016/j.worlddev.2012.09.002.

Gupta, Sanjeev, Alvar Kangur, Chris Papageorgiou, and Abdoul Wane. 2014. "EfficiencyAdjusted Public Capital and Growth." World Development 57 (May): 164-78. doi:10.1016/j.worlddev.2013.11.012.

Haites, Erik. 2011. “Climate Change Finance." Climate Policy 11: 963-69.

Halsnæs, Kirsten, and Amit Garg. 2011. “Assessing the Role of Energy in Development and Climate Policies-Conceptual Approach and Key Indicators." World Development 39 (6): 987-1001. doi:10.1016/j.worlddev.2010.01.002. 
Hutton, Guy. 2012. "Global Costs and Benefits of Drinking-Water Supply and Sanitation Interventions to Reach the MDG Target and Universal Coverage". WHO/HSE/WSH/12.01. http://www.who.int/water_sanitation_health/publications/2012/globalcosts.pdf

IEA. 2013. “Global Land Transport Infrastructure Requirements: Estimating Road and Railway Infrastructure Capacity and Costs to 2050." http://www.iea.org/publications/freepublications/publication/transportinfrastru ctureinsights_final_web.pdf.

IPCC. 2014a. Climate Change 2014: Impacts, Adaptation, and Vulnerability IPCC Working Group II Contribution to AR5. http://www.ipcc.ch/report/ar5/wg2/.

IPCC. 2014b. “Climate Change 2014: Mitigation of Climate Change IPCC Working Group III Contribution to AR5." https://www.ipcc.ch/report/ar5/wg3/.

ITU. 2014. World Telecommunication/ICT Indicators Database, 18th Edition. http://www.itu.int/en/ITU-D/Statistics/Pages/publications/wtid.aspx. Jacoby, Hanan C. 2000. "Access to Markets and the Benefits of Rural Roads." Economic Journal 110 (465): 713-37.

Jakob, Michael, Claudine Chen, Sabine Fuss, Annika Marxen, and Ottmar Edenhofer. 2015. "Development Incentives for Fossil Fuel Subsidy Reform." Nature Clim. Change 5 (8): 709-12.

Jakob, Michael, and Ottmar Edenhofer. 2014. “Green Growth, Degrowth, and the Commons." Oxford Review of Economic Policy 30(3). 
Jakob, Michael, and Jan Christoph Steckel. 2014. "How Climate Change Mitigation Could Harm Development in Poor Countries: How Climate Change Mitigation Could Harm." Wiley Interdisciplinary Reviews: Climate Change 5 (2): 161-68. doi:10.1002/wcc.260.

Jakob, Michael, Jan Christoph Steckel, Christian Flachsland, and Lavinia Baumstark. 2015. “Climate Finance for Developing Country Mitigation: Blessing or Curse?" Climate and Development 7 (1): 1-15. doi:10.1080/17565529.2014.934768.

Jha, Raghbendra. 2004. “Innovative Sources of Development Finance: Global Cooperation in the Twenty-First Century." World Economy 27 (2): 193-214. doi:10.1111/j.1467-9701.2004.00596.x.

Kallbekken, Steffen, Stephan Kroll, and Todd L. Cherry. 2011. "Do You Not like Pigou, or Do You Not Understand Him? Tax Aversion and Revenue Recycling in the Lab." Journal of Environmental Economics and Management 62 (1): 53-64. doi:10.1016/j.jeem.2010.10.006.

Koch, Nicolas, Wolf Heinrich Reuter, Sabine Fuss, and Godefroy Grosjean. 2015. “Permits vs. Offsets under Investment Uncertainty." http://papers.ssrn.com/sol3/papers.cfm?abstract_id=2711321.

Krey, Volker, Gunnar Luderer, Leon Clarke, and Elmar Kriegler. 2014. “Getting from Here to There - Energy Technology Transformation Pathways in the EMF27 Scenarios." Climatic Change 123 (3-4): 369-82. doi:10.1007/s10584-013-0947-5.

Kriegler, Elmar, John P. Weyant, Geoffrey J. Blanford, Volker Krey, Leon Clarke, Jae Edmonds, Allen Fawcett, et al. 2014. "The Role of Technology for Achieving 
Climate Policy Objectives: Overview of the EMF 27 Study on Global Technology and Climate Policy Strategies." Climatic Change 123 (3-4): 353-67. doi:10.1007/s10584-013-0953-7.

Luderer, Gunnar, Valentina Bosetti, Michael Jakob, Marian Leimbach, Jan C. Steckel, Henri Waisman, and Ottmar Edenhofer. 2011. "The Economics of Decarbonizing the Energy System - results and Insights from the RECIPE Model Intercomparison." Climatic Change 114 (1): 9-37. doi:10.1007/s10584-011-0105$\mathrm{x}$.

Malik, Arun S., and Stephen C. Smith. 2012. "Adaptation to Climate Change in LowIncome Countries: Lessons from Current Research and Needs from Future Research." Climate Change Economics 03 (02): 1250005. doi:10.1142/S2010007812500054.

Mattoo, Aaditya, and Arvind Subramanian. 2012. "Equity in Climate Change: An Analytical Review." World Development 40 (6): 1083-97. doi:10.1016/j.worlddev.2011.11.007.

Never, Babette, and Joachim Betz. 2014. "Comparing the Climate Policy Performance of Emerging Economies." World Development 59 (July): 1-15. doi:10.1016/j.worlddev.2014.01.016.

OECD. 2014. “Aid Statisitcs." http://www.oecd.org/dac/stats/.

Onyeji, ljeoma, Morgan Bazilian, and Patrick Nussbaumer. 2012. “Contextualizing Electricity Access in Sub-Saharan Africa." Energy for Sustainable Development 16 (4): 520-27. doi:10.1016/j.esd.2012.08.007. 
Pachauri, Shonali. 2014. “Household Electricity Access a Trivial Contributor to CO2 Emissions Growth in India." Nature Climate Change 4 (12): 1073-76. doi:10.1038/nclimate2414.

Pachauri, Shonali, Bas J van Ruijven, Yu Nagai, Keywan Riahi, Detlef P van Vuuren, Abeeku Brew-Hammond, and Nebojsa Nakicenovic. 2013. "Pathways to Achieve Universal Household Access to Modern Energy by 2030." Environmental Research Letters 8 (2): 024015. doi:10.1088/1748-9326/8/2/024015.

Rao, Narasimha D., Keywan Riahi, and Arnulf Grubler. 2014. “Climate Impacts of Poverty Eradication." Nature Climate Change 4 (9): 749-51.

Raupach, Michael R., Steven J. Davis, Glen P. Peters, Robbie M. Andrew, Josep G. Canadell, Philippe Ciais, Pierre Friedlingstein, Frank Jotzo, Detlef P. van Vuuren, and Corinne Le Quéré. 2014. "Sharing a Quota on Cumulative Carbon Emissions." Nature Climate Change 4 (10): 873-79. doi:10.1038/nclimate2384.

Schneider, Lambert. 2009. “A Clean Development Mechanism with Global Atmospheric Benefits for a Post-2012 Climate Regime." International Environmental Agreements: Politics, Law and Economics 9 (2): 95-111. doi:10.1007/s10784-0099095-9.

Shami, Mahvish. 2012. “The Impact of Connectivity on Market Interlinkages: Evidence from Rural Punjab." World Development 40 (5): 999-1012. doi:10.1016/j.worlddev.2011.11.019.

UN. 2013. "World Population Prospects: The 2012 Revision." http://esa.un.org/wpp/. UNFCCC. 1992. United Nations Framework Convention on Climate Change. 
UNFCCC. 2010. “Decision 1/CP.16."

http://unfccc.int/resource/docs/2010/cop16/eng/07a01.pdf\#page=2.

UNFCCC. 2011. “Decision 1/CP.17."

http://unfccc.int/resource/docs/2011/cop17/eng/09a01.pdf\#page=2.

UNTT Working Group on Sustainable Development Financing. 2013. "UN System Task

Team on the Post-2015 UN Development Agenda Working Group on 'Financing for Sustainable Development'. Executive Summary."

https://sustainabledevelopment.un.org/content/documents/2091Executive \%20Summary-UNTT\%20WG\%20on\%20SDF.pdf.

Winkler, Harald, André Felipe Simões, Emilio Lèbre la Rovere, Mozaharul Alam, Atiq Rahman, and Stanford Mwakasonda. 2011. "Access and Affordability of Electricity in Developing Countries." World Development 39 (6): 1037-50. doi:10.1016/j.worlddev.2010.02.021.

World Bank. 2012. "Turn Down the Heat: Why a $4^{\circ} \mathrm{C}$ Warmer World Must Be Avoided." http://documents.worldbank.org/curated/en/2012/11/17097815/turn-downheat-4\%C2\%BOc-warmer-world-must-avoided.

World Bank. 2013. “Financing For Development Post-2015."

https://www.worldbank.org/content/dam/Worldbank/document/Poverty \%20documents/WB-PREM\%20financing-for-development-pub-10-11-13web.pdf.

World Bank. 2014. World Development Indicators.

http://databank.worldbank.org/data/views/variableselection/selectvariables.asp $x$ ?source=world-development-indicators. 
World Bank, and Ecofys. 2015. “Carbon Pricing Watch 2015 : An Advance Brief from the State and Trends of Carbon Pricing 2015 Report." http://documents.worldbank.org/curated/en/2015/05/24528977/carbonpricing-watch-2015-advance-brief-state-trends-carbon-pricing-2015-reportreleased-late-2015. 


\section{Tables and Figures}

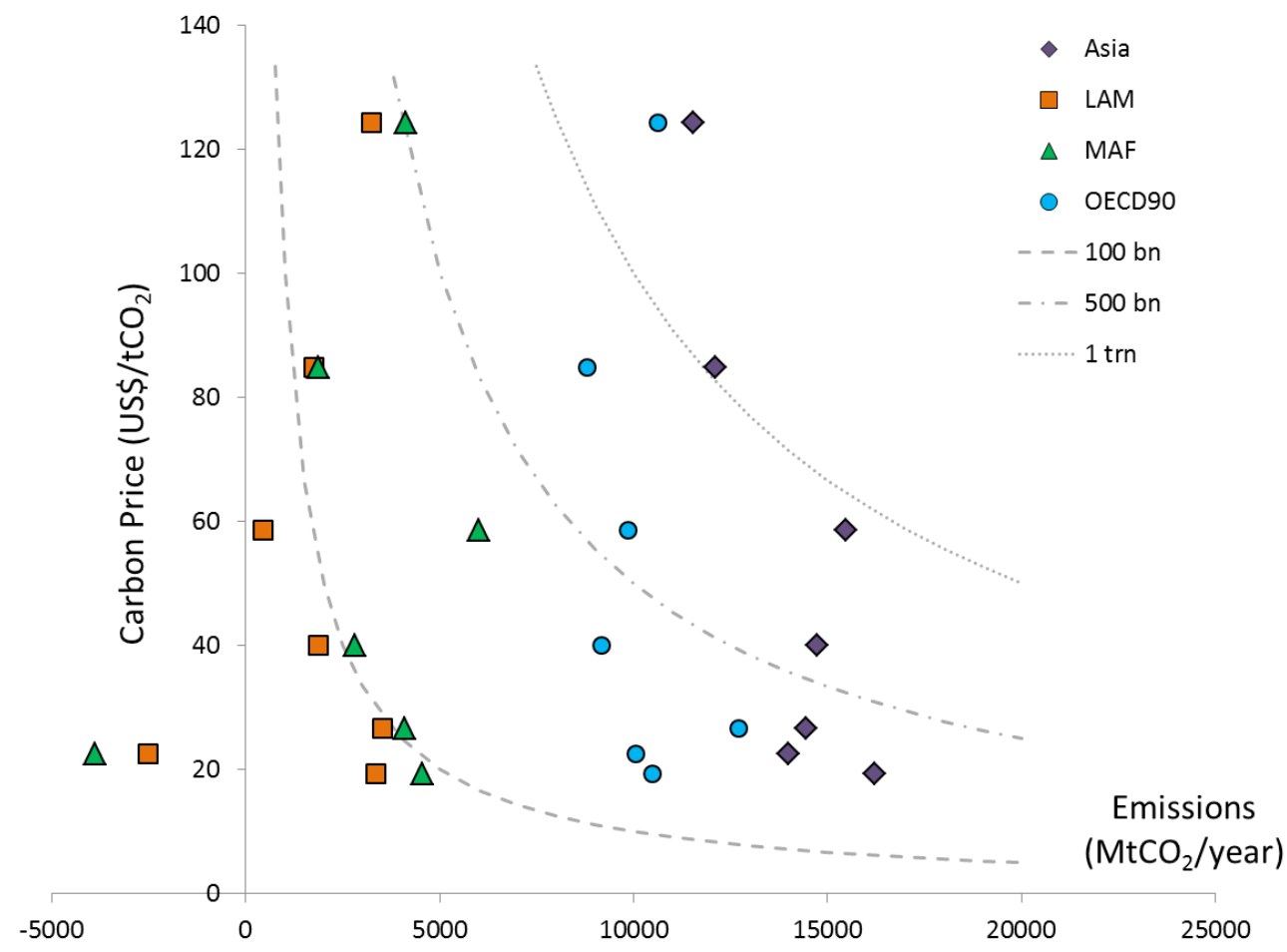

Figure 1: Emissions and carbon prices (in year 2005 US\$) in the year 2020 for the 450ppm scenario, which exhibits an even chance to limit global warming in the year 2100 to below $2^{\circ} \mathrm{C}$ compared to the pre-industrial level. Data are from the EM-F27 model comparison (Blanford, Kriegler, and Tavoni 2014; Krey et al. 2014; Kriegler et al. 2014) for four regions: Asia (purple), Latin America (orange), Middle East and Africa (green) and the OECD (blue). Negative emissions imply removal of emissions from the atmosphere from e.g. biomass and CCS (BECCS) or afforestation. The dashed iso-revenue curves indicate all points that correspond to revenues from carbon pricing of US\$100 bn, 500 bn, and 1 trn, respectively. 


\begin{tabular}{|c|c|c|c|c|}
\hline VARIABLES & $\begin{array}{c}(1) \\
\text { p2020 }\end{array}$ & $\begin{array}{c}(2) \\
\text { p2020 }\end{array}$ & $\begin{array}{c}\text { (3) } \\
\text { p2020 }\end{array}$ & $\begin{array}{c}(4) \\
\text { p2020 }\end{array}$ \\
\hline PPM450 & $\begin{array}{c}27.79 \\
(37.99)\end{array}$ & $\begin{array}{c}62.56^{* *} \\
(23.77)\end{array}$ & $\begin{array}{l}27.79 \\
(39.34)\end{array}$ & $\begin{array}{c}63.67^{* *} \\
(24.15)\end{array}$ \\
\hline NoCCS & $\begin{array}{c}8.422 \\
(37.99)\end{array}$ & $\begin{array}{l}52.08^{*} \\
(28.94)\end{array}$ & $\begin{array}{l}8.422 \\
(39.34)\end{array}$ & $\begin{array}{l}53.44 * \\
(29.57)\end{array}$ \\
\hline LimBio & $\begin{array}{c}2.996 \\
(37.99)\end{array}$ & $\begin{array}{c}11.51 \\
(28.18)\end{array}$ & $\begin{array}{l}2.996 \\
(39.34)\end{array}$ & $\begin{array}{c}11.79 \\
(28.90)\end{array}$ \\
\hline PPM450_NoCCS & $\begin{array}{l}99.77^{*} \\
(56.90)\end{array}$ & & $\begin{array}{l}100.9 * \\
(58.36)\end{array}$ & \\
\hline PPM450_LimBio & $\begin{array}{c}16.27 \\
(55.10)\end{array}$ & & $\begin{array}{l}16.07 \\
(56.79)\end{array}$ & \\
\hline AIM & $\begin{array}{c}15.23 \\
(38.19)\end{array}$ & $\begin{array}{l}-0.213 \\
(36.36)\end{array}$ & & \\
\hline GCAM & $\begin{array}{l}-8.103 \\
(38.19)\end{array}$ & $\begin{array}{l}-23.54 \\
(36.36)\end{array}$ & & \\
\hline IMAGE & $\begin{array}{c}22.79 \\
(42.47)\end{array}$ & $\begin{array}{c}1.050 \\
(39.01)\end{array}$ & & \\
\hline MESSAGE & $\begin{array}{l}-2.054 \\
(38.19)\end{array}$ & $\begin{array}{l}-17.49 \\
(36.36)\end{array}$ & & \\
\hline POLES & $\begin{array}{c}12.96 \\
(38.19)\end{array}$ & $\begin{array}{l}-2.475 \\
(36.36)\end{array}$ & & \\
\hline REMIND & $\begin{array}{l}95.60 * * \\
(38.19)\end{array}$ & $\begin{array}{l}80.16^{* *} \\
(36.36)\end{array}$ & & \\
\hline WITCH & $\begin{array}{c}14.87 \\
(39.92)\end{array}$ & $\begin{array}{l}-7.919 \\
(37.31)\end{array}$ & & \\
\hline Constant & & & $\begin{array}{c}21.61 \\
(27.82)\end{array}$ & $\begin{array}{c}3.673 \\
(23.40)\end{array}$ \\
\hline $\begin{array}{l}\text { Observations } \\
\text { R-squared }\end{array}$ & $\begin{array}{c}39 \\
0.625\end{array}$ & $\begin{array}{c}39 \\
0.577\end{array}$ & $\begin{array}{c}39 \\
0.292\end{array}$ & $\begin{array}{c}39 \\
0.220\end{array}$ \\
\hline
\end{tabular}




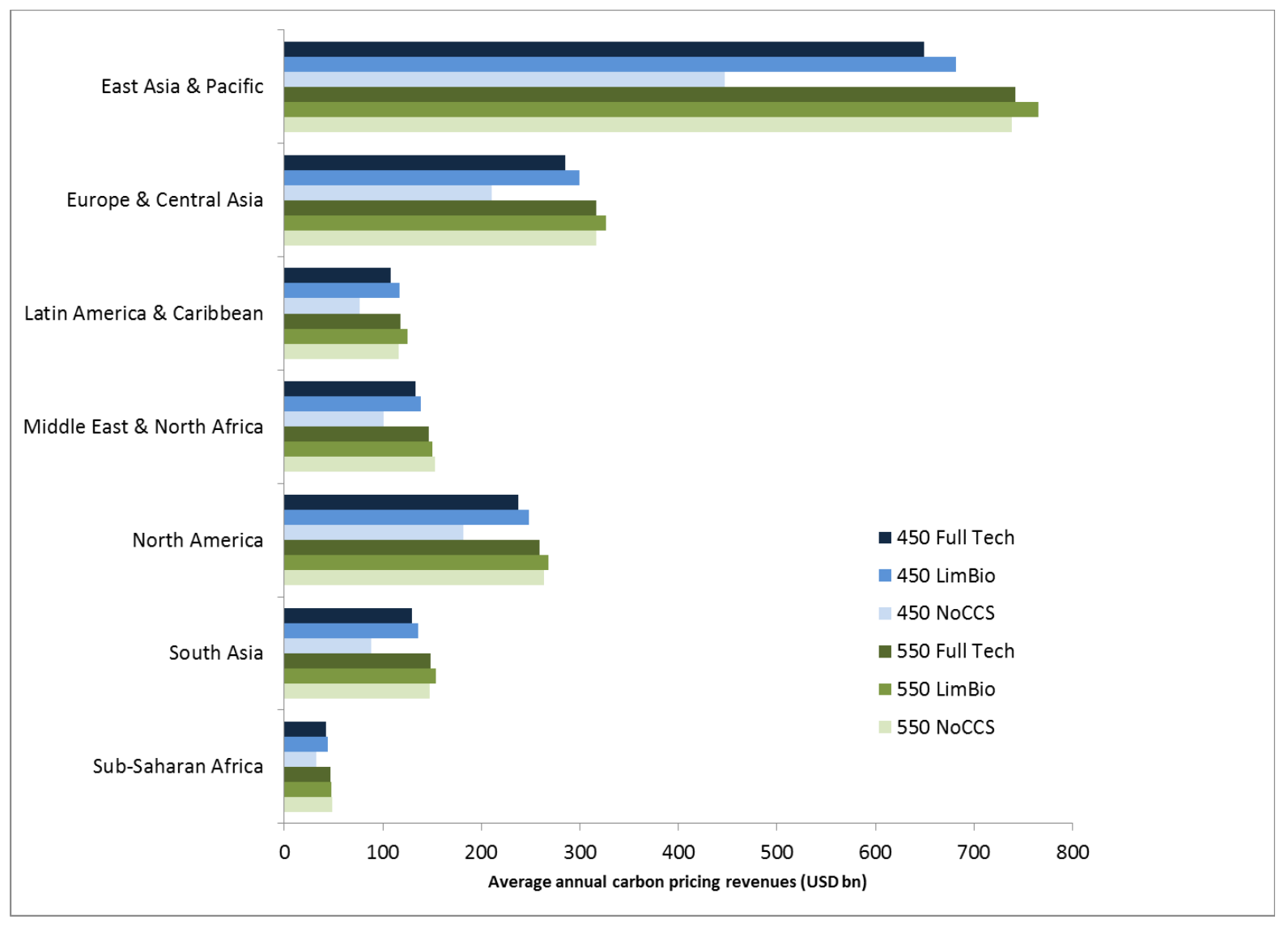

Figure 2: Average annual revenues from carbon pricing under different stabilization scenarios (450ppm and $550 \mathrm{ppm}$ ) and technological assumptions (full technology portfolio, limited availability of biomass, and unavailability of CCS) by region in constant year 2005 US\$ bn. 


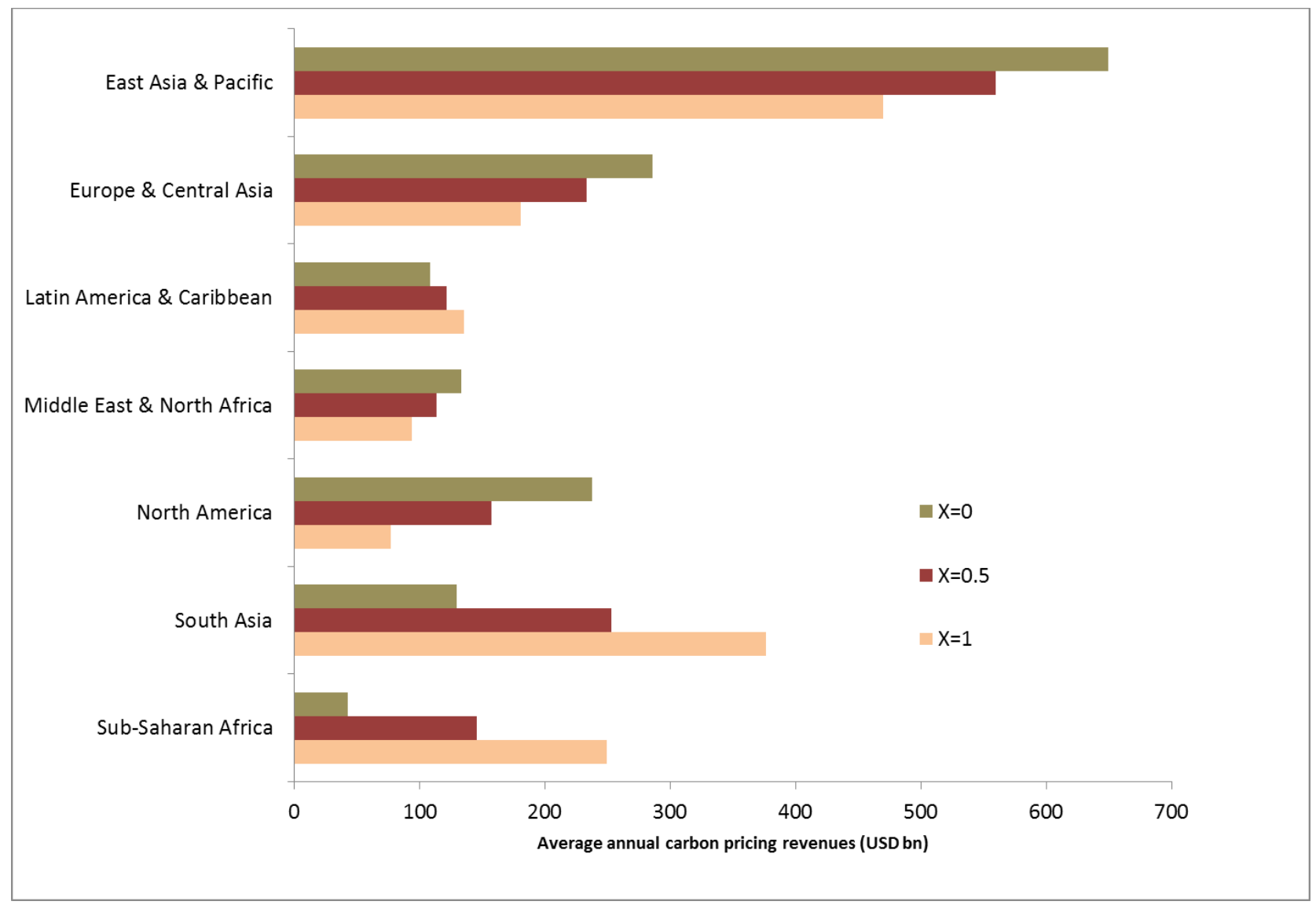

Figure 3: Average annual revenues from carbon pricing under different assumptions on how revenues are distributed by region in constant year 2005 US\$ bn. The case of $X=0$ denotes domestic carbon pricing, whereas $X=1$ corresponds to an equal per-capita distribution of global carbon pricing revenues, and $\mathrm{X}=0.5$ the average between the former two cases. 


\begin{tabular}{|l|l|c|l|c|c|}
\hline & $\begin{array}{l}\text { Water } \\
\text { (percentage } \\
\text { without } \\
\text { access) }\end{array}$ & $\begin{array}{l}\text { Sanitation } \\
\text { (percentage } \\
\text { without } \\
\text { access) }\end{array}$ & $\begin{array}{l}\text { Electricity } \\
\text { (percentage } \\
\text { without } \\
\text { access) }\end{array}$ & $\begin{array}{l}\text { ICT } \\
\text { (percentage } \\
\text { without } \\
\text { access) }\end{array}$ & $\begin{array}{l}\text { Roads } \\
\text { (percentage } \\
\text { unpaved) }\end{array}$ \\
\hline East Asia \& Pacific & 8.8 & 30.6 & 4.8 & 29.3 & 40.1 \\
\hline Europe \& Central Asia & 2.0 & 6.5 & 0.0 & 14.2 & 23.1 \\
\hline Latin America \& Caribbean & 6.2 & 18.4 & 5.2 & 23.0 & 81.8 \\
\hline Middle East \& North Africa & 9.2 & 11.1 & 5.3 & 13.8 & 21.9 \\
\hline North America & 0.8 & 0.1 & 0.0 & 1.1 & 0.0 \\
\hline South Asia & 10.6 & 61.8 & 25.6 & 67.9 & 46.9 \\
\hline Sub-Saharan Africa & 36.7 & 69.6 & 68.1 & 59.8 & 79.6 \\
\hline Global & $\mathbf{1 1 . 3}$ & $\mathbf{3 6 . 0}$ & $\mathbf{1 6 . 8}$ & $\mathbf{3 7 . 4}$ & $\mathbf{3 1 . 6}$ \\
\hline
\end{tabular}

Table 2: Share of population lacking access to electricity, water, sanitation, telecommunication and share of unpaved roads by region according to World Bank classification. All data are for the year 2010. Source: World Bank (2014), ITU (2014), Pachauri et al. (2013). 

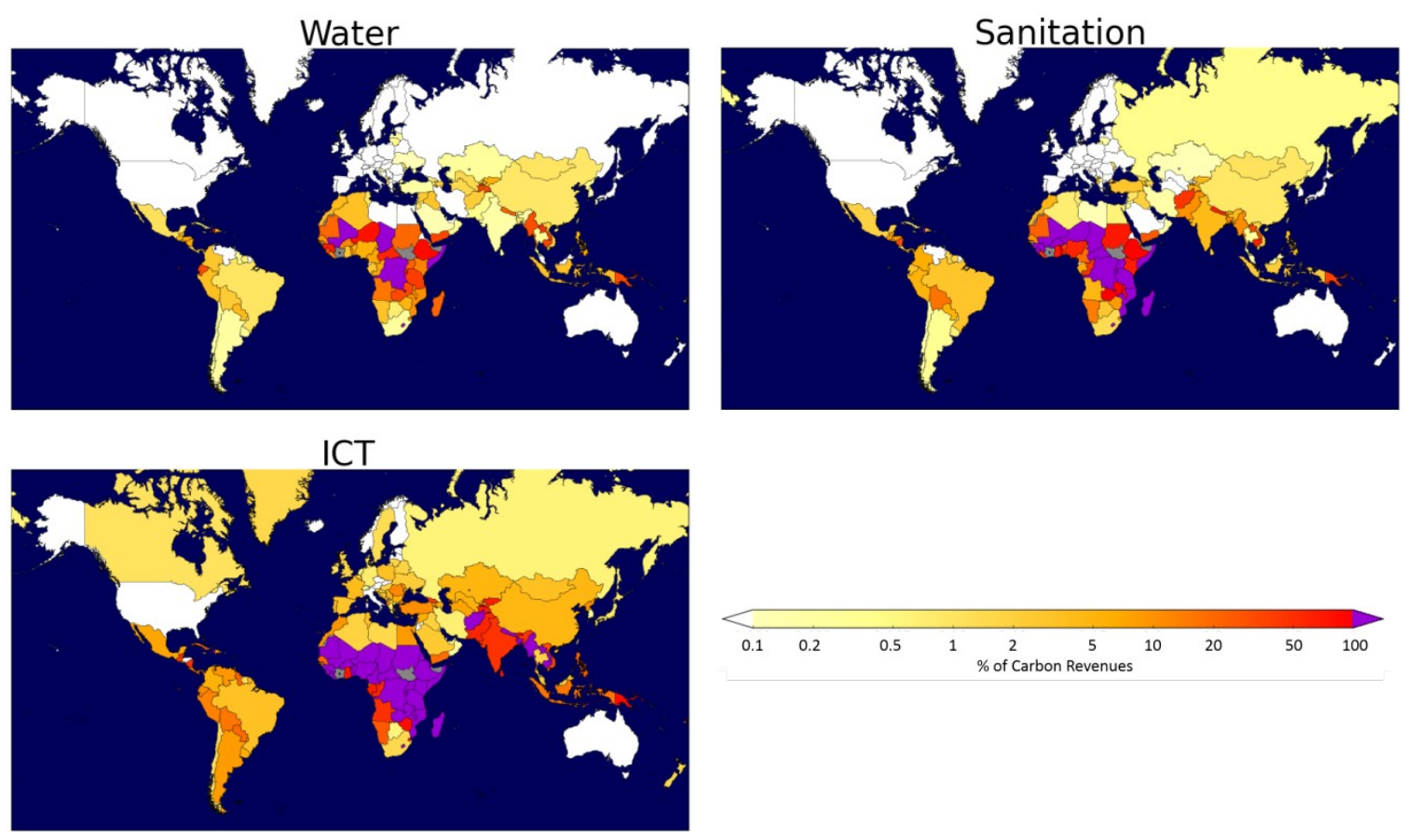

Figure 4: Share of carbon pricing revenues required to finance universal access to infrastructure under domestic carbon pricing (i.e. without transfers between countries) fo the 450ppm scenario with full technological availability. (a) Water, (b) Sanitation, (c) Electricity, (d) Telecommunication, and (e) costs of paving all unpaved roads. For description of data and sources see Section 3. Darker colors indicate higher shares, and dark purple shares exceeding one. Grey areas denote countries for which data are not available. Please note logarithmic scale.
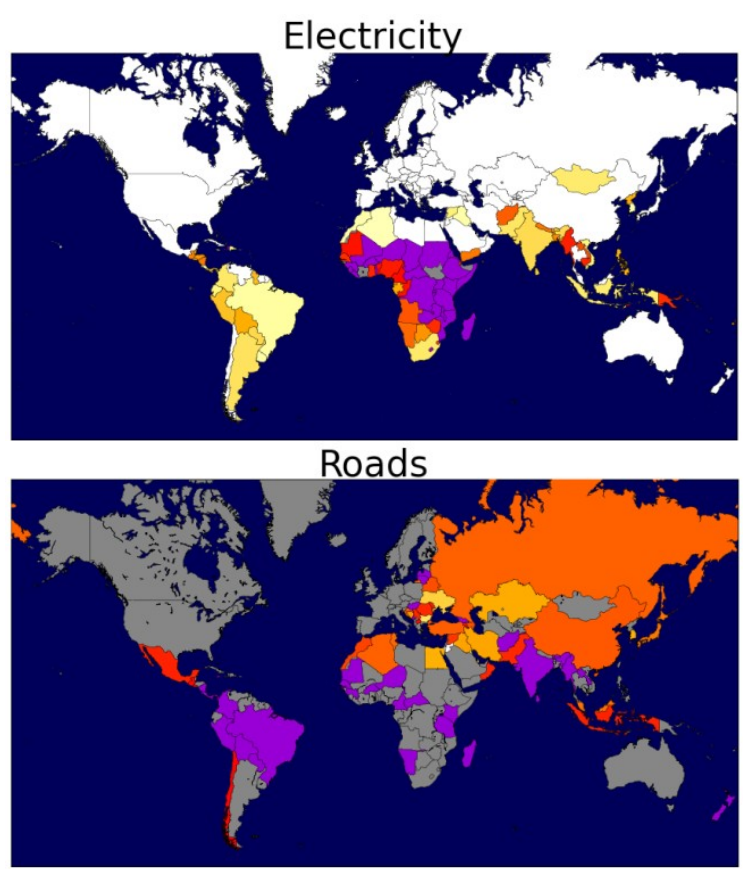

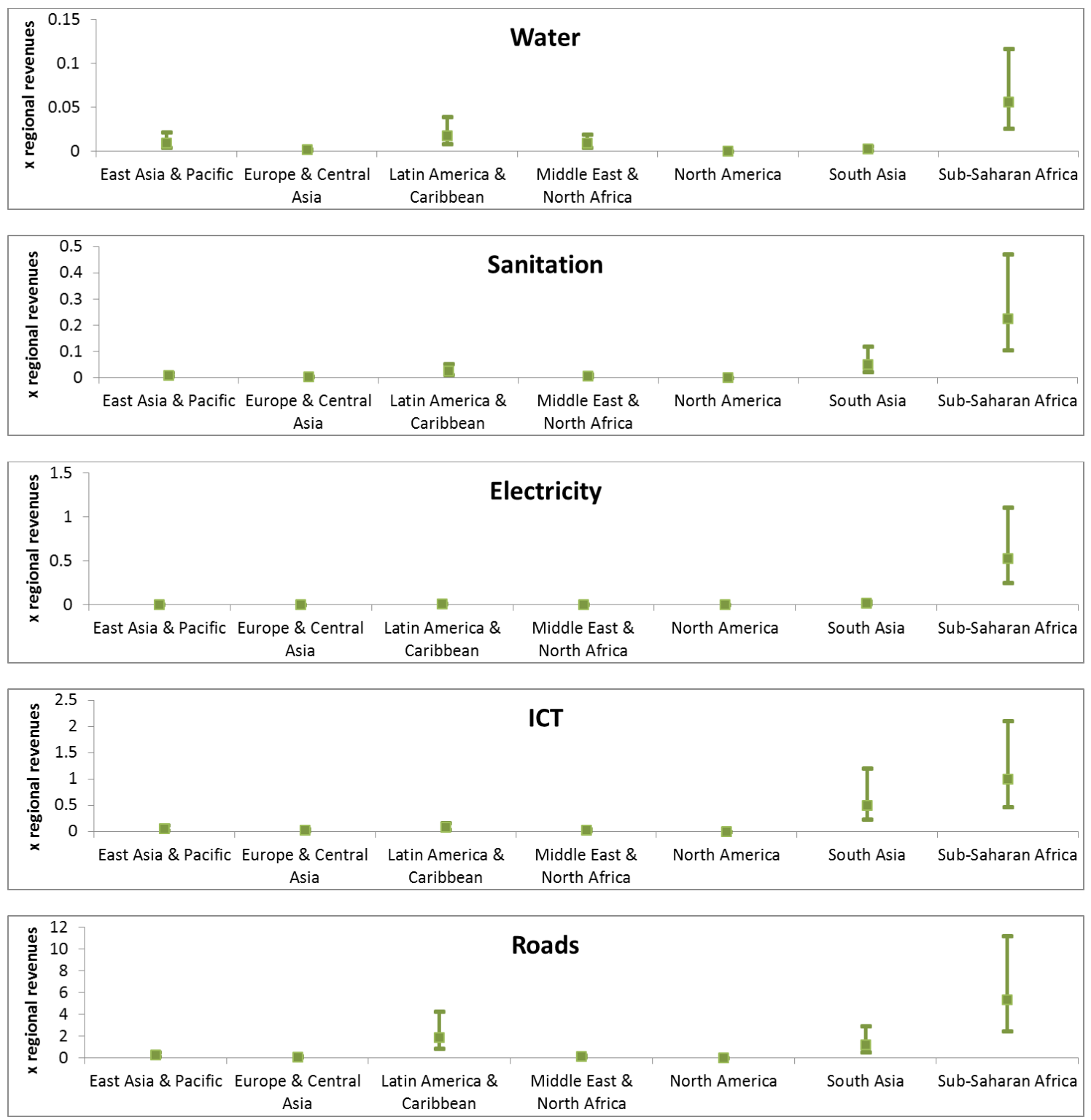

Figure 5: Results of sensitivity analysis showing minimum and maximum investment requirements (whiskers) as well as median values relative to carbon pricing revenues by region. Values larger than one indicate that revenues would be insufficient to cover investment needs. Please note different scales. 


\section{Appendix}
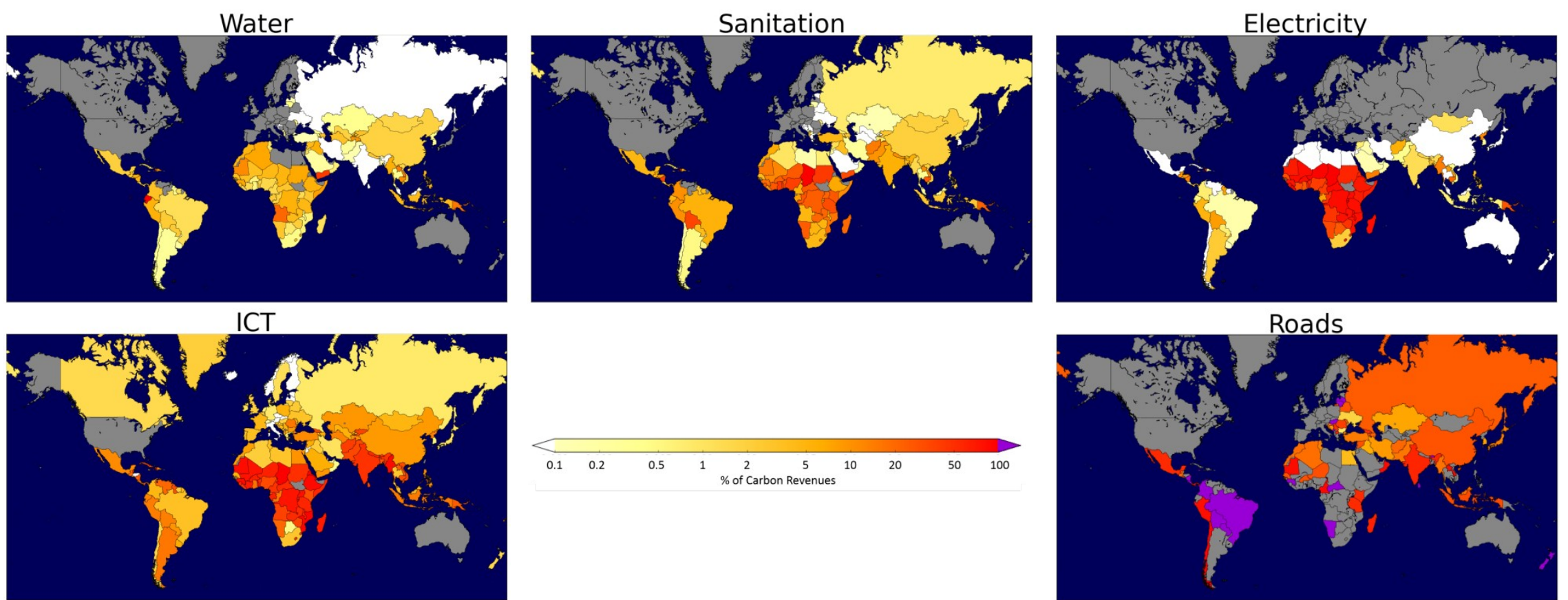

Figure A1: Share of carbon pricing revenues required to finance universal access to infrastructure for the 450ppm scenario with full technological availability, assuming that global carbon pricing revenues are distributed by the average between 'no redistribution' and 'equal per-capita' (i.e. X=0.5). (a) Water, (b) Sanitation, (c) Electricity, (d)

Telecommunication, and (e) costs of paving all unpaved roads. For description of data and sources see Section 3. Darker colors indicate higher shares, and dark purple shares exceeding one. Grey areas denote countries for which data are not available. Please note logarithmic scale. 